\title{
Electronic Theses and Dissertations Programs: A Review of the Critical Success Factors
}

\author{
Behrooz Rasuli, Sam Solaimani, and Mehdi Alipour-Hafezi
}

An early version of this study has been presented in the 19th International Symposium on Electronic Theses and Dissertations (Lille, France). Our gratitude to the reviewers and participants of the ETD national policies session for their constructive feedback. Furthermore, we are grateful to Dr. Joachim Schöpfel (Université Lille 3) for his suggestions on an early version of this manuscript.

Electronic Theses and Dissertations (ETDs) programs have been recognized as one of the most effective channels through which theses and dissertations can be made available to academic communities and beyond. ETD program management, however, needs to be aware of the Critical Success Factors (CSFs) throughout the process of design and development of ETDs. As the name implies, CSFs are those considerations decisive in achieving the projects' mission and goals. Based on a structured review of the existing literature about ETDs, this study identifies the CSFs that are crucial for the implementation of ETD programs. By comparing and classifying the identified CSFs, the study conceptualizes a generic framework comprising five generic dimensions: management and organization, participation, content, technology, and service. The framework can help the ETDs community, both scholars and practitioners, to make informed decisions on how to allocate effort and resources to the development, implementation, or improvement of ETD programs.

\section{Introduction}

Advancement of research and education depends on replication of scientific findings ${ }^{1}$ so that developing methods and tools for sharing such findings among a wider range of users has always been an important concern in theory and practice. Electronic Theses and Dissertations (ETDs) is one of the relatively new channels and was launched in the early '90s to facilitate access to students' theses and dissertations. ${ }^{2}$ According to Park, Nam, and Oh, there is an increasing interest in integrated ETDs, ${ }^{3}$ and the number of ETD programs, in particular, at an institutional level, is increasing every year. ${ }^{4}$

Behrooz Rasuli is a PhD Candidate in Library and Information Science at Iranian Research Institute for Information Science and Technology (IranDoc); email: rasouli@students.irandoc.ac.ir. Sam Solaimani is an Associate Professor in the Center for Marketing and Supply Chain Management at Nyenrode Business University, The Netherlands; email: S.Solaimani@nyenrode.nl. Mehdi Alipour-Hafezi is an Assistant Professor in the Department of Knowledge and Information Science, Faculty of Psychology and Education Sceince, at Allameh Tabataba'i University (ATU), Tehran, Iran; email: meh.hafezi@gmail.com. He is also a Visiting Lecturer at Iranian Research Institute for Information Science and Technology (IranDoc); email: alipour@irandoc.ac.ir. @2019 Behrooz Rasuli, Sam Solaimani, and Mehdi Alipour-Hafezi. 
Many institutions around the world have emphasized the implementation of ETD programs, and a few countries have attempted to do this at a national level. Nevertheless, design and implementation (including maintenance) of ETD programs is not straightforward. The diversity of various stakeholders, standards, and policies renders the design and implementation ETD programs an arduous and uncertain process. There is a vast set of factors that may cause an ETD program to cease or may lead to feasibility and viability issues. According to Teper and Kraemer, the success of a program is not always short term; more often than not, a long-term perspective should be taken into account. ${ }^{5}$

In the lexicon of management, Critical Success Factor (CSF) refers to those factors that directly affect the realization of a plan or project. The term "success factors" was first used by Daniel, ${ }^{6}$ and Rockart ${ }^{7}$ evolved it into CSF, a elaborating that it is helpful for executives to define their significant information needs. Ever since, many scholars have provided a definition, but Rockart's definition is one of the most widely accepted: "[CSFs are] the limited number of areas in which results, if they are satisfactory, will ensure successful competitive performance for the organization. They are the few key areas where 'things must go right' for the business to flourish. If results in these areas are not adequate, the organization's efforts for the period will be less than desired." ${ }^{8}$

Although CSF was originally developed as a way to determine the key information needs of top managers, ${ }^{9}$ in recent years this concept has been adopted for various other purposes, including performance evaluation, determination of information requirements, and planning. ${ }^{10}$ The most ambiguous part of CSFs is the S; what does "success" actually mean? Clearly, success is a relative measure, completely dependent on the context where it is used, and it is often related to a mission or goal of a system, corporation, or project. Some authors argue that the frequency of views (such as page views per year) and the "width" of ETD users (like scholars, general public, policy makers) indicate the success. ${ }^{11}$ Some others, such as Müller et al., ${ }^{12}$ argue that the usability of the portal that makes ETDs accessible determines success. As an example, Müller et al. point to the DiVA Portal, which is a tool for finding the theses of students at 47 institutions. As the DiVA Portal makes research publications accessible through the web, its success depends on methods that make the DiVA Portal useful for the users. Generally, no matter what system is used, the measurement of the success of ETD programs is based on their defined goals and objectives, as well as the control of those factors that may predict this success.

While there are several studies on requirements for implementing ETD programs, ${ }^{13}$ there is still a lack of generic frameworks that describe and prescribe effective implementation of ETD programs. This is the gap that this study aims to address. The main objective is to identify the CSFs deemed crucial to the design and implementation of ETD programs.

\section{Background}

According to the literature, CSF has been applied in many domains: for example, education, ${ }^{14}$ knowledge management, ${ }^{15}$ construction, ${ }^{16}$ Internet-of-Things (IoT) ${ }^{17}$ and healthcare. ${ }^{18}$ However, to the best of our knowledge, it has not been dealt with adequately in the context of Library and Information Science (LIS). Unsurprisingly, a search in the Library, Information Science \& Technology Abstracts (LISTA) yielded fewer than 40 articles with a focus on CSFs. The LIS researchers' focus is on various themes, including knowledge management ${ }^{19}$ resource sharing ${ }^{20}$ information centers management, ${ }^{21}$ usage of electronic information resources, ${ }^{22}$ library gateways, ${ }^{23}$ information quality management, ${ }^{24}$ digital libraries (DLs) ${ }_{1}^{25}$ institutional repositories (IRs) ${ }^{26}$ and information systems. ${ }^{27}$ 
There are a few valuable studies on the factors affecting the implementation of institutional repositories but without an explicit focus on CSFs (examples: Cassella, ${ }^{28}$ Giesecke, ${ }^{29}$ Lihitkar and Lihitkar, ${ }^{30}$ Shearer ${ }^{31}$ Thibodeau, ${ }^{32}$ Westell ${ }^{33}$ ). Noteworthy is a study by Fox et al.$^{34}$ that links the success of a global ETD program, such as Networked Digital Library of Theses and Dissertations (NDLTD) to adoption of sensible strategies, suitable standards, interoperability, ${ }^{35}$ and social issues. Materu-Behitsa and Levey emphasize a functional perspective of ETDs, for example, the provisioning of full text to be of great value for the long-term effectiveness of the Database of African Theses \& Dissertations (DATAD) project. ${ }^{36}$

However, within the large body of knowledge on ETD, literature about CSFs in ETDs is relatively scarce, and what exists appears to be highly fragmented. To fill this gap, the present study reports the key topics about CSFs relevant to ETD design and development. Further, the study synthesizes extent knowledge into a coherent framework.

\section{Methodology}

To achieve the goal of this study, a systematic literature review was conducted. According to Fink, "research literature review is a systematic, explicit, and reproducible method for identifying, evaluating, and synthesizing the existing body of completed and recorded work produced by researchers, scholars, and practitioners." ${ }^{\prime 37}$ The review is structured according to the broadly accepted process proposed by Higgins and Green. ${ }^{38}$

- Step 1. Research question: What are the CSFs in the development and implementation of ETD programs?

- Step 2. Searching for studies: searching ("electronic theses and dissertation") OR ("electronic thesis and dissertation*") in title/abstract/keywords until June 1, 2016 through bibliographic databases (Library Science Database, Web of Science, Scopus, LISTA, and LISA) and ETDs symposiums' papers.

- Step 3. Selecting studies: Selecting journal articles, conference papers, and book sections that include possible success factors of institutional/national/regional/global ETD programs.

- Step 4. Analyzing data: synthesizing the data using categorization schemes.

- Step 5. Presenting results: critical success factors are presented in a table.

- Step 6. Interpreting results and drawing conclusions

As part of the second step, a search query was formulated to screen major (accessible) bibliographic databases. ETD symposiums and conferences are another rich source of insight. However, the proceedings are not always indexed in search engines. Therefore, the repositories of the main symposiums and conferences were found (mainly on the NDLTD platform ${ }^{39}$ or, alternatively, through an Internet Archive: Wayback Machine ${ }^{40}$ ) and explored (see table 1). The time span of the search for symposiums is from 2000 until 2015.

Table 2 shows the number of records extracted from the bibliographic databases and ETD symposiums and the search was conducted in May 2016. As presented in table 2, the systematic search for articles resulted in collection of 1,140 records. In preparing the data for analysis, all of the records were downloaded and imported into a local database created with EndNote (version X7.5). By removing the duplicates, a total of 833 records were selected for further analysis.

\footnotetext{
* All asterisks in search queries are wildcards for searching.
} 


\begin{tabular}{|l|l|l|}
\hline \multicolumn{2}{|l|}{ ETD Symposiums (2000-2015) } \\
\hline Year & \multicolumn{1}{|c|}{ Location } & \multicolumn{1}{c|}{ Website } \\
\hline 2000 & Florida, USA & http://docs.ndltd.org/dspace/handle/2340/15 \\
\hline 2001 & California, USA & http://docs.ndltd.org/dspace/handle/2340/14 \\
\hline 2002 & Utah, USA & http://docs.ndltd.org/dspace/handle/2340/13 \\
\hline 2003 & Berlin, Germany & http://docs.ndltd.org/dspace/handle/2340/10 \\
\hline 2004 & Kentucky, USA & http://docs.ndltd.org/dspace/handle/2340/7 \\
\hline 2005 & Sydney, Australia & $\begin{array}{l}\text { https://web.archive.org/web/20050104183151/http://adt.caul.edu. } \\
\text { au:80/etd2005/default.html }\end{array}$ \\
\hline 2006 & Quebec City, Canada & http://docs.ndltd.org/dspace/handle/2340/5 \\
\hline 2007 & Uppsala, Sweden & http://epc.ub.uu.se/etd2007/index.html \\
\hline 2008 & Aberdeen, Scotland & $\begin{array}{l}\text { https://web.archive.org/web/20081219151623/http://rgu.ac.uk:80/etd/ } \\
\text { home }\end{array}$ \\
\hline 2009 & Pennsylvania, USA & http://www.library.pitt.edu/etd2009 \\
\hline 2010 & Texas, USA & $\begin{array}{l}\text { https://web.archive.org/web/20140530115946/https://conferences.tdl. } \\
\text { org/utlibraries/index.php/utlibraries/etd2010 }\end{array}$ \\
\hline 2011 & Cape Town, South Africa & http://dl.cs.uct.ac.za/conferences/etd2011 \\
\hline 2012 & Lima, Peru & $\begin{array}{l}\text { https://web.archive.org/web/20130919151959/http://etd2012.unmsm. } \\
\text { edu.pe/en/index.asp }\end{array}$ \\
\hline 2013 & Hong Kong, China & http://lib.hku.hk/etd2013/about.html \\
\hline 2014 & Leicester, UK & http://www2.le.ac.uk/library/etd2014 \\
\hline 2015 & Delhi, India & http://etd2015india.in \\
\hline
\end{tabular}

In the third step, the publications' title, abstract, and keywords were screened, which has led to the selection of 95 publications from the databases and 68 proceedings from symposiums and conferences that refer or discuss CSFs in the context of ETD development or implementation.

The analysis, in the fourth step, is based on full-length reading and coding of CSFs in the selected publications. Also in this step, a few publications were excluded mainly because these publications appeared to have a different emphasis than that which was initially indicated in the abstract. The final sample of publications included 39 publications ( 28 journal articles, 7 conference proceedings, and 2 book chapters). Next, all of the identified CSFs were categorized in various dimensions. The CSF models proposed by Lagzian, Abrizah, and Wee ${ }^{41}$ were used as the initial frameworks for the categorization. These models provide CSFs of DLs and IRs that are not too different from ETDs. However, in the categorizing process, the authors excluded changes, creating themes to cover all of the identified codes that emerged in this study. To reach a consensus on how the extracted CSFs should be interpreted, labeled, and structured, the authors organized several meetings. In these meetings, the authors' common understanding and differences of opinion were extensively discussed. In a collaborative way, the authors strove to organize various factors along higher-level dimensions. Iteratively, the dimensions and the underlying factors were adjusted and reshaped to the point that all factors were covered and no further adjustment was necessary (in other words, the saturation point). 


\begin{tabular}{|c|c|c|}
\hline \multicolumn{3}{|c|}{$\begin{array}{c}\text { TABLE } 2 \\
\text { Searching for Literature Process }\end{array}$} \\
\hline Database & Search Query & Records \# \\
\hline $\begin{array}{l}\text { Web of Science (Indexes: SCl- } \\
\text { EXPANDED, SSCl, A\&HCI, CPCI-S, } \\
\text { CPCI-SSH, BKCl-S, BKCI-SSH, ESCI) }\end{array}$ & $\begin{array}{l}\text { TOPIC: ("electronic theses and dissertation*") OR TOPIC: } \\
\text { ("electronic thesis and dissertation*") }\end{array}$ & 79 \\
\hline $\begin{array}{l}\text { Library Science Database } \\
\text { (ProQuest) }\end{array}$ & $\begin{array}{l}\text { all("electronic theses and dissertation*") OR } \\
\text { all("electronic thesis and dissertation*") }\end{array}$ & 81 \\
\hline $\begin{array}{l}\text { LISA: Library \& Information } \\
\text { Science Abstracts (ProQuest) }\end{array}$ & $\begin{array}{l}\text { ab(("electronic theses and dissertation*" OR "electronic } \\
\text { thesis and dissertation*")) OR ti(("electronic theses and } \\
\text { dissertation*" OR "electronic thesis and dissertation*")) } \\
\text { OR su(("electronic theses and dissertation*" OR } \\
\text { "electronic thesis and dissertation*")) }\end{array}$ & 130 \\
\hline Scopus & $\begin{array}{l}\text { (TITLE-ABS-KEY ("electronic theses and dissertation*") } \\
\text { OR TITLE-ABS-KEY ("electronic thesis and dissertation*")) }\end{array}$ & 162 \\
\hline $\begin{array}{l}\text { LISTA: Library, Information } \\
\text { Science \& Technology Abstracts } \\
\text { (EBSCO) }\end{array}$ & $\begin{array}{l}\text { TI ("electronic theses and dissertation*" OR "electronic } \\
\text { thesis and dissertation*") OR SU ("electronic theses and } \\
\text { dissertation*"OR "electronic thesis and dissertation*") } \\
\text { OR AB ("electronic theses and dissertation*" OR } \\
\text { "electronic thesis and dissertation*") OR KW ("electronic } \\
\text { theses and dissertation*" OR "electronic thesis and } \\
\text { dissertation*") }\end{array}$ & 183 \\
\hline $\begin{array}{l}\text { The ACM Digital Library (ACM Full- } \\
\text { Text Collection) }\end{array}$ & $\begin{array}{l}\text { Any Field ("ETD*" OR "Electronic Thesis and Dissertation*" } \\
\text { OR "Electronic Theses and Dissertation*") }\end{array}$ & 14 \\
\hline Sub-total & After removing 307 duplicates & 342 \\
\hline $\begin{array}{l}\text { Retrieved studies presented in } \\
\text { ETD symposiums }\end{array}$ & Retrieving papers presented in ETD symposiums & 491 \\
\hline Total & Database and ETD symposium unique records & 833 \\
\hline
\end{tabular}

\section{Findings}

The first remarkable descriptive finding is that the attention of the ETDs community for CSFs has been increasing in the period from 1997 to 2015 (see figure 1). Furthermore, the D-Lib Magazine (3 articles), Library Hi Tech (3 articles), Library Management (3 articles), and Interlending $\mathcal{E}$ Document Supply (2 articles) together accounted for about 30 percent of the total of the selected articles.

With respect to the main contribution of this study, 45 CSFs were repeatedly underscored as impactful in the design and implementation of ETD programs. These CSFs were clustered in five coherent dimensions, namely: Management and Organization, Participation, Content, Technology, and Service (see figure 2). The five dimensions are detailed below.

\section{Management and Organization}

Management and Organization captures the financial and organizational structure and decision-making process and policies in ETD programs. Developers need to know and regularly meet with key policy-makers and funders throughout ETD programs. Planning a detailed roadmap with clear goals and objectives is required, ${ }^{42}$ which includes scheduling and defining 

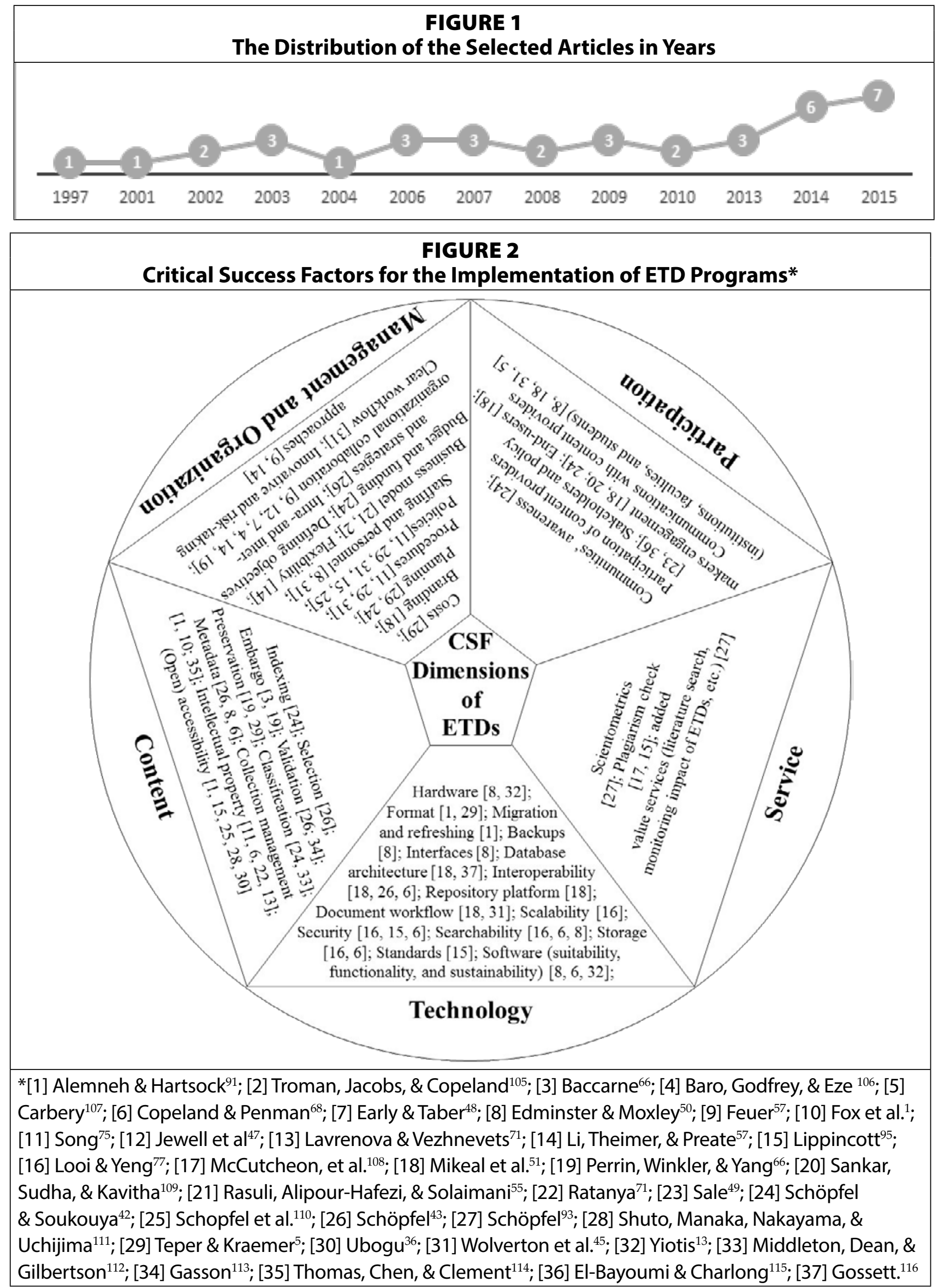
general policies, strategies, and regulations ${ }^{43}$ and creating formal procedures and workflows that facilitate management (that is, collection, arrangement, access, and modification) of the content. ${ }^{44}$ Note that the policies, strategies, regulations, procedures, and workflows may be updated according to new conditions over time; hence, periodic review is considered to be necessary. ${ }^{45}$ In addition, national policies in a country may (and often do) have an effect on ETDs' implementation: for example, local policies regarding data accessibility of institutional repositories, which will result in providing full-text ETDs or only metadata and abstracts for end-users. ${ }^{46}$ Typically, implementation requires collaboration among different groups within an institution or a country, ${ }^{47}$ or even beyond. To a great extent, the success of ETD programs depends on effective communication and collaboration within and between the involved stakeholders ${ }^{48}$ It is important that the participants have periodic meetings to review the process of implementing the ETD program. ${ }^{49}$ Thus, to enhance creativity and collegiality, a diverse team with members from library and information science, computer science, and intellectual property law is suggested. ${ }^{50}$ An image of collective institutions (such as a central library in a university, or a documentation center in a country) is another critical factor that needs to be considered ${ }^{51}$ A trustworthy image helps the branding of ETD programs, which attracts more stakeholders to support and participate in the ETD program.

The financial aspects are another concern of any ETD implementation. ${ }^{52}$ One is the management of costs, which mainly involves the costs of preservation, hardware and software, and staff. ${ }^{53}$ To cover the costs, seeking funds is a crucial activity. ${ }^{54}$ Many ETD programs are open access, and their budget depends on public funding provided by governmental bodies and semigovernmental institutions. ${ }^{55}$ An effective management of financial aspects can be achieved by means of a well thought-out business model with a clear structure to both create and capture value ${ }^{56}$ and to stimulate the entrepreneurial spirit to foster initiative and risktaking that are needed for setting up an ETD program. ${ }^{57}$

\section{Participation}

ETD programs achieve their full potential when there is active engagement of the stakeholders, ${ }^{58}$ especially the content providers. The content providers are individuals or university faculties and departments, or institutions that generate and upload Theses and Dissertations (TDs). Policy makers are other key stakeholders in the ETD network, such as university deans, library directors, and department heads. In general, policy makers are responsible for the project and are involved in the program across various phases of development and implementation. ${ }^{59}$ The end-users are perhaps the most important stakeholders; they vary from students, researchers, trend analysts, to the general public. Their continuous feedback is needed throughout the development phase. ${ }^{60}$ With insights into users' information needs and information-seeking behavior, the developers are able to develop ETD systems and interfaces with high usability and user friendliness. ${ }^{61}$ Efforts should be made to increase the awareness of all participants of the ETDs' network about the program (such as the involved processes, functionalities, opportunities, and challenges). ${ }^{62}$ According to Mikeal et al., as part of the ETD programs, training courses can be organized that improve the communities' awareness of the program. ${ }^{63}$

\section{Content}

Content refers to the collection of Theses and Dissertations (TDs) from content providers and its preparation and provisioning to end-users. The content is directly submitted by individuals, 
faculty members, academic departments, and institutions or indirectly through a harvesting method, which means data gathering from other sources than through students or faculties. ${ }^{64}$ For example, some national programs harvest ETDs via individual institution through their IRs.

It is highly recommended that ETD programs define criteria for the collection management of TDs, including a content selection and a TD validation process to ensure the delivering of valid and high-quality content..$^{65}$ The format of TDs (print, digital, or both) is another aspect that should be decided upon. Some content providers also have specific policies on publication delays due to data sensitivity, deriving articles to submit them for publication in academic journals, which should be taken into consideration in any ETD program. ${ }^{66}$

The quality and accessibility of the content is another important factor and includes topics, such as indexing (assigning appropriate keywords and thesauri to the content), classification (dividing content in a range of subject categories), and describing the content with metadata to improve information retrieval. ${ }^{67}$ Also, digital and physical preservation of TDs appears to be an essential aspect, in particular when it comes to the loss prevention of information. ${ }^{68} \mathrm{According}$ to Teper and Kraemer, preservation involves "binding, conservation, deacidification, care and handling, and reformatting programs." ${ }^{69}$ In ETD programs, digital preservation is advocated as it ensures a greater longevity of the documents. ${ }^{70}$

Copyright is another recurring aspect of ETDs' provisioning. ${ }^{71}$ The content providers' moral, ethical, and economic rights should be clear, and copyright-related issues should be attended to, including declaimers and terms of use and must be published online. ${ }^{72}$ In addition, policies to address copyright infringement, plagiarism, and embargo in ETD programs should be explicit and transparent. ${ }^{73}$ Transparency about these policies is an effective step to avoid content providers' concerns about improper, or misuse of, content. ${ }^{74}$ Related to copyright, the debate on open and semiopen access to TDs has increasingly attracted developers' attention. ${ }^{75}$ While open access leads to less revenue, it does create a network effect in which more and more users are attracted to the ETD program (or platform), thus making it prominent.

\section{Technology}

Technology is the key enabler of an ETD program, and a significant part of the implementation is carried out by Information Technology (IT) staff. Technology dimension refers to a wide range of tools, skills, and activities pertaining to digitization. ${ }^{76}$ It must be emphasized that the infrastructure (both hardware and software) need to be scalable to facilitate new content and run new services if needed, ${ }^{77}$ as well as to cope with interoperability among various content systems. ${ }^{78}$ Mikeal et al. emphasize the role of system architecture in addressing scalability and interoperability. ${ }^{79}$ However, multilayered architecture, including storage, logic, and access layers can address these two domains. ${ }^{80}$

A robust ETD program delivers content to end-users in a seamless way. ${ }^{81}$ Document workflow that represents the entire process from preparing ETDs (collecting TDs) to delivering content to end-users should be defined. ${ }^{82}$ This workflow is defined and implemented in a repository platform, which plays an important role in selecting standards for filing, preserving, describing, and retrieving ETDs. ${ }^{83}$ Also, the searchability of content is underlined. ${ }^{84} \mathrm{DSpace}$ is an example of a widely accepted platform used by the ETD community, with features including organizing and managing content, finding and searching, preserving, making backup, and analyzing usage statistics. ${ }^{85}$ It is suggested that repository platforms facilitate searchability and accessibility of content in an ETD database. ${ }^{86}$ 
Users' interface is another important factor with considerable impact on the satisfaction and experience of end-users. ${ }^{87}$ In this regard, user-friendliness combined with the ability to navigate (for instance, visualizing tools) is emphasized. ${ }^{88}$ Moreover, full-text searching and metadata-enabled searching are other important elements in designing a user interface. ${ }^{89}$

Security is considered to be another crucial aspect of ETD program design and implementation. ${ }^{90}$ Security refers to the tools, methodologies, and processes that aim to protect content, users' privacy, and the source code used in developing the application software.

Finally, to have a sustainable ETD program, migration and data-refreshing formats are required. ${ }^{91}$ With the advancement of different technologies, existing formats for saving content (such as PDF) may be replaced with other formats. Therefore, refreshing the content formats will help the program to serve its users continuously. The decisions around formats are also relevant with respect to data backups. ${ }^{92}$

\section{Service}

The service dimension refers to the values created for end-users. ${ }^{93}$ For example, scientometrics are considered very useful for users of ETDs, and the dimension should capture research trends, measure impact through usage and citations, and show collaboration networks. ${ }^{94}$ Several ETD programs, such as the ETD programs of Iran and India, have developed different dashboards for their content providers to monitor their statistics and impact. Through these dashboards, content providers-including institutions, university departments, faculties, and students - can compare their performance with one another.

Another essential service is a plagiarism check. ${ }^{95}$ Some countries, such as Iran and India, have tools integrated for plagiarism checks in their national ETD programs. ${ }^{96}$ This service is available in the Iranian program for the content providers and other institutions. Therefore, this service can be considered an incentive to attract more participants to the ETD program.

Another value-adding service is "literature search," ETD program. With this service, search specialists help the end-users to find related TDs in a certain area. However, this is a paid service, charged per user request. For providing more services, ETD developers can request information from their users about their needs and demands. In this regard, "need assessment" surveys may help ETD programs to provide more relevant and creative services. The provision of a wide range of helpful services will make ETDs useful and encourage stakeholders to (financially) support the programs.

\section{Conclusion}

An institutional ETD program is an institutional repository of theses and dissertations. According to Lynch and Lippincott, institutional repositories play a key role in digital scholarship and are broadly recognized as an essential infrastructure for academic research..$^{98}$ Thus, the successful implementation of ETDs has a direct implication for national and international research and education.

In this study, a systematic literature review was conducted to shed light on the existing literature of ETDs. The findings of this study indicate that the existing ETD literature focuses on at least five areas of management and organization, participation, content, technology, and service. Strikingly, the technology dimension consists of more variables than all of the other dimensions, which implies that the ETD community is more focused and nuanced on an understanding of this dimension. Perhaps the technical background of the authors in the field of ETDs has played a role in this. Moreover, the technological advancements in digitization, 
data networks, and management helped the emergence of ETDs in the early '80s, which may be another underlying reason for the nonproportional focus on technology. In this study, it is argued that all dimensions should receive equal attention.

More specifically, it can be concluded that, while technical issues are crucial in the early stages of the development of ETDs, organizational and managerial issues can ensure the sustainability and viability of the program in the later stages. Furthermore, since an ETD program has to be compatible or connected with other information discovery systems (such as current research information systems [CRISs], online public access catalogs [OPACs], and specialized scientific databases), ensuring the quality of content is vital, which requires the cooperation of all participants. Without the participation of (all) content providers, either at an institution or country level, a self-sustaining ETD program is barely viable. While some programs prefer to mandate depositing TDs (such as the national ETD programs in India and Iran), others prefer voluntary submission (such as EThOS in the United Kingdom and Theses Canada). Either way, to have active participation of the content providers, incentive mechanisms need to be in place to encourage content providers. ${ }^{99}$

Drawing on the findings of this study, it can be stated that the business viability of ETD programs seems to be contingent upon five dimensions: (1) management and organization; (2) participation; (3) content; (4) technology; and (5) service. A great number of the reviewed articles consider that the management and organization of the CSF throughout the entire design and implementation cycle of the ETD programs is the most crucial, including the policies regarding required technologies and tools, the partners and the forms of participation, the content types, and the collecting methods, as well as the quantity and quality of service level. At a more operational level, the technology dimension is of greatest concern, with technical specifications and infrastructural issues coming to the fore throughout the design and implementation of the ETD program.

Enabled by management and organizational facilities and supported by technological infrastructure, the three remaining dimensions can be effectively organized. As such, participation refers to attracting and encouraging content providers and other stakeholders, such as policy-makers, researchers, and the general public. While the content providers are a critical part of any ETD program, the provided content is equally important. Content is mainly the theses and dissertations. The content should be made available after verification, indexing/ abstracting and via proper channels to the "right" segment of users. The content is made usable and useful through services. The ETD services include the basic functionality of the programs, such as basic search and access to metadata and full-text. Some examples are content delivery, print facilities, visualizing information, preparing networking among authors, assigning DOI to documents, as well as the size and quality of content. It can be argued that the five dimensions are integrative and work as a system. Equal attention to all dimensions enhances the likelihood of effective and sustainable ETD programs (see figure 3).

Furthermore, the findings of this study imply that management, technology, and service are three common dimensions of CSFs in implementing ETDs, IRs, and DLs. However, despite the commonalities, the corresponding CSFs are not identical per se. For instance, according to Lagzian, Abrizah, and Wee, self-archive practices seem crucial for IRs, given the voluntary participation of its content providers, ${ }^{100}$ but virtually irrelevant for ETDs since students' submission of TDs is often mandatory. Another example is IRs that are implemented by a team from various departments and specialties in an institution, ${ }^{101}$ for which the "people" dimension is 


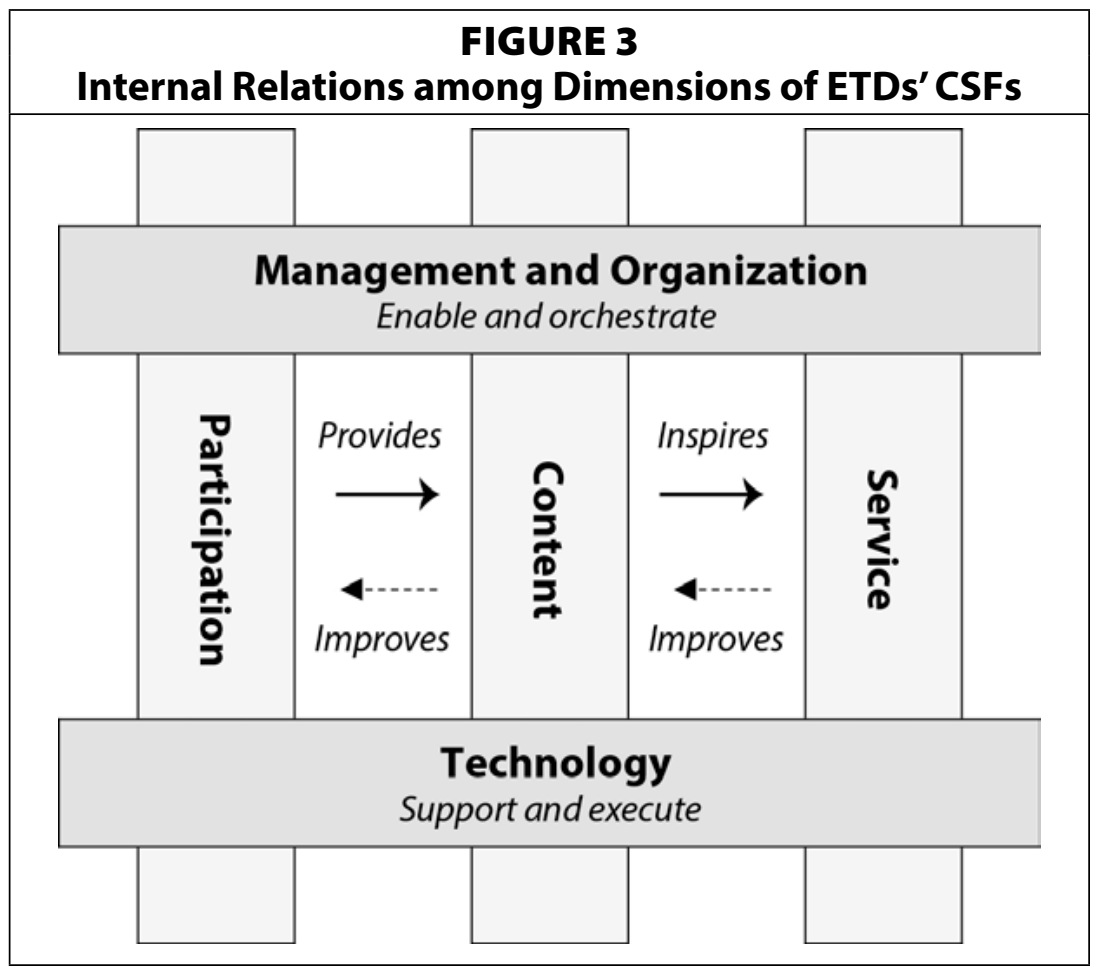

evidently crucial. However, the ETDs are often implemented exclusively by university libraries and librarians, skillful in collecting, organizing, and disseminating of ETDs, and leading the "people" to be a variable and not a dimension in the CSF.

The findings of this research can help developers and managers in the design, implementation, and maintenance of the ETD programs, for instance, by using the proposed integrative framework and the underlying $46 \mathrm{CSF}$; they can also be useful for evaluating existing programs. Practitioners can prepare a roadmap covering CSFs and draw associations among different factors. ETD programs' managers should have clear policies for addressing CSFs while preparing their action plans. From an academic viewpoint, the framework provides a coherent structure in which other future studies can be positioned. The study also provides a comprehensive view of the existing body of knowledge on ETDs and relevant CSFs.

\section{Limitations}

This study has several limitations. First, although great effort was made to collect as many possible relevant articles as possible, undoubtedly more could have been added (such as digital library, institutional repositories). However, given the large number of collected papers, it is fair to argue that adding more articles would not necessarily change the overall structure of the framework. Also, the framework and the variables are, to some extent, resting on the subjective understanding and interpretation of the authors; however, this is a generic shortcoming in any qualitative research. To address this shortcoming and improve the internal validity of the study, the authors organized iterative discussions among themselves to reach a consensus view on how various CSF should be interpreted and structured within the proposed framework. The repetitive occurrence of the CSFs was also taken into consideration.

\section{Future Research}

Needless to say, the results of this study show commonalities with other IT-driven projects (such as Wong and Tein ${ }^{102}$ ), mainly due to the fact that ETD projects are often based on existing IT infrastructure, initiated and led by IT-savvy staff. A broader generalizability can be achieved by comparing the findings of this study with other IT implementation or digitalization projects in general, and specifically with IT systems in library and information management context, such as the rollout of specialized databases, CRISs, IRs, or DL platforms. Business 
feasibility is another highly relevant yet underresearched area in the ETD literature. Without a clear alignment between the business model and the underlying operational infrastructure and processes, the business feasibility and viability of ETD programs are untenable (compare with Solaimani ${ }^{103}$ ). To this end, finding relevant metrics is imperative in evaluating and validating the implementability and progress, ${ }^{104}$ for instance, to assess the ETDs' added value for various stakeholders.

\section{Notes}

1. Edward A. Fox et al., “NDLTD: Encouraging International Collaboration in the Academy," DESIDOC Bulletin of Information Technology 17, no. 6 (1997).

2. Joan K. Lippincott and Clifford A. Lynch, "ETDs and Graduate Education: Programs and Prospects," Research Library Issues: A Bimonthly Report from ARL, CNI, and SPARC 270 (2010): 6-15.

3. Eun G. Park, Young-joon Nam, and Sanghee Oh, "Integrated Framework for Electronic Theses and Dissertations in Korean Contexts," Journal of Academic Librarianship 33, no. 3 (2007): 338-46.

4. Yin Zhang, Kyiho Lee, and Bum-Jong You, "Usage Patterns of an Electronic Theses and Dissertations System," Online Information Review 25, no. 6 (2001): 370-78.

5. Thomas H. Teper and Beth Kraemer, "Long-Term Retention of Electronic Theses and Dissertations," College \& Research Libraries 63, no. 1 (2002): 61-72.

6. D. Ronald Daniel, “Management Information Crisis," Harvard Business Review : HBR 39, no. 5 (1961): 111-21.

7. John F. Rockart, “Chief Executives Define Their Own Data Needs,” Harvard Business Review 57, no. 2 (1979): 81-93.

8. Ibid.

9. Ibid.

10. Ken Peffers, Charles E. Gengler, and Tuure Tuunanen, “Extending Critical Success Factors Methodology to Facilitate Broadly Participative Information Systems Planning," Journal of Management Information Systems 20, no. 1 (2003): 51-85.

11. Xiaocan Wang, Natalie Bulick, and Valentine Muyumba, "Publishing Student Scholarship: Exploring the ETD Initiative at a Medium-Sized Institution," OCLC Systems \& Services 30, no. 4 (2014): 232-48.

12. Eva Müller et al., "Akademisk Forskning Online-Academic Research in Sweden Online," in Proceedings of the Sixth International Symposium on Electronic Theses and Dissertations, Humboldt-Universität zu Berlin (2003): 204-08, doi:10.18452/1154.

13. Park, Nam, and Oh, "Integrated Framework for Electronic Theses and Dissertations in Korean Contexts," 338-46; Sílvia Barcellos Southwick, "The Brazilian Electronic Theses and Dissertations Digital Library: Providing Open Access for Scholarly Information," Ciencia da Informacao 35, no. 2 (2006): 103-10; Eun G. Park, Qing Zou, and David McKnight, "Electronic Thesis Initiative: Pilot Project of Mcgill University, Montreal," Program 41, no. 1 (2007): 81-91; Kristin Yiotis, "Electronic Theses and Dissertation (ETD) Repositories: What Are They? Where Do They Come From? How Do They Work?" OCLC Systems \& Services: International Digital Library Perspectives 24, no. 2 (2008): 101-15; Networked Digital Library of Theses and Dissertations (NDLTD), "Manage ETDs," (2013), available online at http://www.ndltd.org/resources/manage-etds [accessed 12 November 2018]; Sharon Reeves, "How to Set Up an ETD Program," (2013), available online at http://www.ndltd.org/resources/manage-etds/setup-an-etd-program [accessed 12 November 2018].

14. Thierry Volery and Deborah Lord, "Critical Success Factors in Online Education," International Journal of Educational Management 14, no. 5 (2000): 216-23.

15. Kuan Yew Wong, "Critical Success Factors for Implementing Knowledge Management in Small and Medium Enterprises," Industrial Management \& Data Systems 105, no. 3 (2005): 261-79.

16. Victor Sanvido et al., "Critical Success Factors for Construction Projects," Journal of Construction Engineering and Management 118, no. 1 (1992): 94-111.

17. Sam Solaimani, Harry Bouwman, and Fernando Secomandi, "Critical Design Issues for the Development of Smart Home Technologies," Journal of Design Research 11, no. 1 (2013): 72-90.

18. Ronnie Ben-Zion, Nava Pliskin, and Lior Fink, "Critical Success Factors for Adoption of Electronic Health Record Systems: Literature Review and Prescriptive Analysis," Information Systems Management 31, no. 4 (2014): 296-312.

19. Yi-Chan Chung, Chih-Hung Tsai, and Yau-Wen Hsu, "Research on the Correlation among Critical Success Factors, of Knowledge Management, Executive Degree of Knowledge Management Activities and New Product Development Performance in Taiwan's High-Tech Firms," Journal of Information \& Knowledge Management 6, no. 
4 (2007): 261-70; Chris Kimble and Isabelle Bourdon, "Some Success Factors for the Communal Management of Knowledge," International Journal of Information Management 28, no. 6 (2008): 461-67; Franz Lehner and Nicolas Haas, "Knowledge Management Success Factors: Proposal of an Empirical Research," Electronic Journal of Knowledge Management 8, no. 1 (2010): 79-90; Ali Mohaghar, Mehdi Shami Zanjani, and Mozhgan Nouri, "Identification and Ranking of Critical Success Factors of Knowledge Management Using Fuzzy Quality Function Deployment Approach: A Case Study," Journal of Information Processing \& Management 28, no. 4 (2013): 1037-68; Nor Intan Saniah Sulaiman et al., "Success Factors in Knowledge Sharing Behaviour among Student Bloggers," Proceedings of the European Conference on Knowledge Management 2 (2013): 702-11; Mohammadbashir Sedighi et al., "Evaluating Critical Success Factors Model of Knowledge Management: An Analytic Hierarchy Process (Ahp) Approach," International Journal of Knowledge Management 11, no. 3 (2015): 17-36.

20. Sirous Alidousti, Maryam Nazari, and Mohammad Abooyee Ardakan, "A Study of Success Factors of Resource Sharing in Iranian Academic Libraries," Library Management 29, no. 8 (2008): 711-28.

21. Ragna Seidler-de Alwis and Simone Fühles-Ubach, "Success Factors for the Future of Information Centres, Commercial and Public Libraries: A Study from Germany," Interlending \& Document Supply 38, no. 3 (2010): 183-88; Simha R. Magal, Houston H. Carr, and Hugh J. Watson, "Critical Success Factors for Information Center Managers," MIS Quarterly (1988): 413-25; Simha R. Magal and Houston H. Carr, "An Investigation of the Effects of Age, Size, and Hardware Option on the Critical Success Factors Applicable to Information Centers," Journal of Management Information Systems 4, no. 4 (1988): 60-76.

22. U.S. Millawithanachchi, "Electronic Resources Usage by Postgraduates at the University of Colombo: Identifying the Critical Success Factors," Annals of Library \& Information Studies 59, no. 1 (2012): 53-63.

23. K. Calhoun, Z. Koltay, and E. Weissman, "Library Gateway: Project Design, Teams, and Cycle Time," Library Resources and Technical Services 43, no. 2 (1999): 114-22.

24. Saša Baškarada and Andy Koronios, "A Critical Success Factor Framework for Information Quality Management," Information Systems Management 31, no. 4 (2014): 276-95.

25. Fatemeh Lagzian, Abdullah Abrizah, and Mee Chin Wee, "An Identification of a Model for Digital Library Critical Success Factors," Electronic Library 31, no. 1 (2013): 5-23.

26. Fatemeh Lagzian, Abdullah Abrizah, and Mee Chin Wee, "Critical Success Factors for Institutional Repositories Implementation," Electronic Library 33, no. 2 (2015): 196-209; Mary Westell, "Institutional Repositories: Proposed Indicators of Success," Library Hi Tech 24, no. 2 (2006): 211-26; Kenneth Thibodeau, "If You Build It, Will It Fly? Criteria for Success in a Digital Repository," JoDI: Journal of Digital Information 8, no. 2 (2007): 2; Kathleen Shearer, "Institutional Repositories: Towards the Identification of Critical Success Factors," Canadian Journal of Information and Library Science/La revue candienne des sciences de l'information et de bibliothèconomie 27, no. 3 (2002/2003); Maria Cassella, "Institutional Repositories: An Internal and External Perspective on the Value of Irs for Researchers' Communities," Liber Quarterly 20, no. 2 (2010).

27. Ben-Zion, Pliskin, and Fink, "Critical Success Factors for Adoption of Electronic Health Record Systems," 296-312; Wing S. Chow and Ha Wai On, "Determinants of the Critical Success Factor of Disaster Recovery Planning for Information Systems," Information Management \& Computer Security 17, no. 3 (2009): 248-75; Tao Zhou, "Examining the Critical Success Factors of Mobile Website Adoption," Online Information Review 35, no. 4 (2011): 636-52; Farajollah Rahnavard and Mehrdad Gholami, "Critical Success Factors in Implementation of Executive Information Systems: A Case Study," Journal of Information Processing \& Management 27, no. 3 (2012): 667-80.

28. Cassella, "Institutional Repositories: An Internal and External Perspective on the Value of IRs for Researchers' Communities."

29. Joan Giesecke, "Institutional Repositories: Keys to Success," Journal of Library Administration 51, no. 5/6 (2011): 529-42.

30. Shalini Ramdas Lihitkar and R.S. Lihitkar, "Electronic Theses and Dissertations (ETDs) in India: A Comparative Study," Library Hi Tech News 31, no. 2 (2014): 9-14.

31. Shearer, "Institutional Repositories: Towards the Identification of Critical Success Factors."

32. Thibodeau, "If You Build It, Will It Fly?" 2.

33. Westell, "Institutional Repositories: Proposed Indicators of Success," 211-26.

34. Fox et al., "NDLTD: Encouraging International Collaboration in the Academy."

35. The ability of computer and information systems or software to interact, exchange and make use of information; for example, exchanging metadata between an institutional repository and a global ETD program.

36. Felix N. Ubogu, "Spreading the ETD Gospel: A Southern Africa Perspective," International Information and Library Review 33, no. 2/3 (2001): 249-59.

37. Arlene Fink, Conducting Research Literature Reviews: From Paper to the Internet (Washington, DC: SAGE Publications, 2014).

38. Julian P.T. Higgins and Sally Green, Cochrane Handbook for Systematic Reviews of Interventions Version 5.1.0 
[Updated March 2011] (The Cochrane Collaboration, 2011), available from www.handbook.cochrane.org [accessed 12 November 2018].

39. Networked Digital Library of Theses and Dissertations, available online at docs.ndltd.org/dspace/community-list [accessed 02 November 2018].

40. Internet Archive Wayback Machine, available online at https://web.archive.org/web/20081219151623/http:// rgu.ac.uk:80/etd/home/ [accessed 10 November 2018].

41. Lagzian, Abrizah, and Wee, "An Identification of a Model for Digital Library Critical Success Factors," 5-23; Lagzian, Abrizah, and Wee, "Critical Success Factors for Institutional Repositories Implementation," 196-209.

42. Joachim Schöpfel and Maebena Soukouya, "Providing Access to Electronic Theses and Dissertations: A Case Study from Togo," D-Lib Magazine 19, no. 11/12 (2013), doi:10.1045/november2013-schopfel.

43. Joachim Schöpfel, "Adding Value to Electronic Theses and Dissertations in Institutional Repositories," D-Lib Magazine 19, no. 3/4 (2013), doi:10.1045/march2013-schopfel.

44. Teper and Kraemer, "Long-Term Retention of Electronic Theses and Dissertations," 61-72.

45. Robert E. Wolverton et al., "The Development and Assessment of ETD Initiatives," in Electronic Theses and Dissertations: Developing Standards and Changing Practices for Libraries and Universities, eds. Robert E. Wolverton et al. (New York: Rotledge, 2009).

46. Clifford A. Lynch and Joan K. Lippincott, "Institutional Repository Deployment in the United States as of Early 2005," D-Lib Magazine 11, no. 9 (2005): 1-11.

47. Christine Jewell, William Oldfield, and Sharon Reeves, "University of Waterloo Electronic Theses: Issues and Partnerships," Library Hi Tech 24, no. 2 (2006): 183.

48. Mary G. Early and Anne Marie Taber, "Evolving in Collaboration: Electronic Thesis and Dissertation Workflows in North Carolina," Collaborative Librarianship 2, no. 1 (2010): 4-18.

49. Arthur Sale, "The Impact of Mandatory Policies on ETD Acquisition," D-Lib Magazine 12, no. 4 (2006), doi:10.1045/april2006-sale.

50. J. Edminster and J. Moxley, "Graduate Education and the Evolving Genre of Electronic Theses and Dissertations," Computers and Composition 19, no. 1 (2002): 89-104.

51. Adam Mikeal et al., "Large-Scale ETD Repositories: A Case Study of a Digital Library Application," Proceedings of the ACM/IEEE Joint Conference on Digital Libraries (2009): 135-144, doi:10.1145/1555400.1555423.

52. Zyad Alreemy et al., "Critical Success Factors (Csfs) for Information Technology Governance (Itg)," International Journal of Information Management 36, no. 6 (2016): 907-16.

53. Teper and Kraemer, "Long-Term Retention of Electronic Theses and Dissertations," 61-72.

54. Schöpfel and Soukouya, "Providing Access to Electronic Theses and Dissertations."

55. Schöpfel and Soukouya, "Providing Access to Electronic Theses and Dissertations"; Behrooz Rasuli, Mehdi Alipour-Hafezi, and Sam Solaimani, "Understanding Electronic Theses and Dissertations through a Business Model: Perspective: The Case of Irandoc ETDs," in 18th International Symposium on Electronic Theses and Dissertations, At New Delhi, India Conference Proceedings, (New Delhi, India, 2015); Behrooz Rasuli, Mehdi Alipour-Hafezi, and Sam Solaimani, "Analyzing National Electronic Theses and Dissertations Programs from Business Model Perspective: Cross-Case Analysis," Online Information Review 42, no. 3 (2018).

56. Rasuli, Alipour-Hafezi, and Solaimani, "Understanding Electronic Theses and Dissertations through a Business Model: Perspective: The Case of Irandoc ETDs"; Rasuli, Alipour-Hafezi, and Solaimani, "Analyzing National Electronic Theses and Dissertations Programs from Business Model Perspective: Cross-Case Analysis."

57. Gabor Feuer, "ETD on a Shoestring," Library Management 35, no. 4/5 (2014): 259-70; Yuan Li, Sarah H. Theimer, and Suzanne M. Preate, "Campus Partnerships Advance Both ETD Implementation and IR Development. A Win-Win Strategy at Syracuse University," Library Management 35, no. 4/5 (2014): 398-404.

58. Mikeal et al., “Large-Scale ETD Repositories: A Case Study of a Digital Library Application."

59. Ibid.

60. Ibid.

61. Edminster and Moxley, "Graduate Education and the Evolving Genre of Electronic Theses and Dissertations," 89-104.

62. Schöpfel and Soukouya, "Providing Access to Electronic Theses and Dissertations."

63. Mikeal et al., "Large-Scale ETD Repositories: A Case Study of a Digital Library Application."

64. M.A. Gonçalves, R.K. France, and E.A. Fox, "Marian: Flexible Interoperability for Federated Digital Libraries," in Research and Advanced Technology for Digital Libraries (Berlin: Springer Berlin Heidelberg, 2001): 173-86, doi:10.1007/3-540-44796-2_16.

65. Schöpfel, "Adding Value to Electronic Theses and Dissertations in Institutional Repositories."

66. Rudi Baccarne, "A Bachelor and Master Theses Portal: Specific Needs and Business Opportunities for the DoKS Repository Tool," in Openness in Digital Publishing: Awareness, Discovery and Access-Proceedings of the 11th 
International Conference on Electronic Publishing, (Vienna, Austria, 2007); J.M. Perrin, H.M. Winkler, and L. Yang, "Digital Preservation Challenges with an ETD Collection: A Case Study at Texas Tech University," Journal of Academic Librarianship 41, no. 1 (2015): 98-104.

67. Schöpfel and Soukouya, "Providing Access to Electronic Theses and Dissertations"; Edminster and Moxley, "Graduate Education and the Evolving Genre of Electronic Theses and Dissertations," 89-104; Susan Copeland and Andrew Penman, "The Development and Promotion of Electronic Theses and Dissertations (ETDs) within the UK," New Review of Information Networking 10, no. 1 (2004): 19-32.

68. Teper and Kraemer, "Long-Term Retention of Electronic Theses and Dissertations," 61-72; Perrin, Winkler, and Yang, "Digital Preservation Challenges with an ETD Collection: A Case Study at Texas Tech University," 98.

69. Teper and Kraemer, “Long-Term Retention of Electronic Theses and Dissertations," 61-72.

70. Devika P. Madalli, Sunita Barve, and Saiful Amin, "Digital Preservation in Open-Source Digital Library Software," Journal of Academic Librarianship 38, no. 3 (2012): 161-64.

71. Copeland and Penman, "The Development and Promotion of Electronic Theses and Dissertations (ETDs) within the UK," 19-32; O.A. Lavrenova and A.A. Vezhnevets, "Structure and Implementation of the RSL Dissertations Digital Library," in Proceedings of the RCDL 2003, St. Petersburg, Russia (Moscow: Russian Foundation Basic Research, 2003); Felicitas C. Ratanya, "Electronic Theses and Dissertations (ETD) as Unique Open Access Materials: Case of the Kenya Information Preservation Society (Kips)," Library Hi Tech News 27, no. 4/5 (2010): 15-20; S. Ian, "Promoting Open Access to Scholarly Data: A Case Study of the Electronic Thesis and Dissertation (ETD) Project at the Simon Fraser University Library," Data Science Journal 6, Suppl. (2007): S70-S88.

72. Susan Copeland, "Electronic Theses and Dissertations," in Digitisation Perspectives, ed. Ruth Rikowski (Rotterdam: SensePublishers, 2011).

73. Angela M. McCutcheon, "Impact of Publishers' Policy on Electronic Thesis and Dissertation (ETD) Distribution Options within the United States," (dissertation, College of Education of Ohio University, 2010).

74. Nancy H. Seamans, "Electronic Theses and Dissertations as Prior Publications: What the Editors Say," Library Hi Tech 21, no. 1 (2003): 56-61.

75. Ian Song, "Promoting Open Access to Scholarly Data: A Case Study of the Electronic Thesis and Dissertation (ETD) Project at the Simon Fraser University Library," Data Science Journal 6, Suppl. (2007): S70-S78.

76. Copeland and Penman, "The Development and Promotion of Electronic Theses and Dissertations (ETDs) within the UK," 19-32.

77. E.N. Looi and S.W. Yeng, "The Inevitable Future of Electronic Theses and Dissertations within Malaysia Context," in Digital Libraries: Technology and Management of Indigenous Knowledge for Global Access. ICADL 2003. Lecture Notes in Computer Science, vol 2911, T.M.T. Sembok, H.B. Zaman, H. Chen, S.R. Urs, SH. Myaeng (eds), (Springer, Berlin, Heidelberg, 2003): 340-350.

78. Mikeal et al., “Large-Scale ETD Repositories: A Case Study of a Digital Library Application."

79. Ibid.

80. W. Ryan Richardson, Venkat Srinivasan, and Edward A. Fox, "Knowledge Discovery in Digital Libraries of Electronic Theses and Dissertations: An NDLTD Case Study," International Journal on Digital Libraries 9, no. 2 (2008): 163-71.

81. Mikeal et al., "Large-Scale ETD Repositories: A Case Study of a Digital Library Application."

82. Adam Mikeal et al., "Developing a Common Submission System for ETDs in the Texas Digital Library," available online at http://hdl.handle.net/1969.1/5679 [accessed 13 November 2018].

83. Sarah Potvin and Santi Thompson, "An Analysis of Evolving Metadata Influences, Standards, and Practices in Electronic Theses and Dissertations," Library Resources \& Technical Services 60, no. 2 (2016): 99-114.

84. Looi and Yeng, "The Inevitable Future of Electronic Theses and Dissertations within Malaysia Context."

85. DSpace Direct website, available online at dspacedirect.org/features [accessed 10 November 2018].

86. Looi and Yeng, "The Inevitable Future of Electronic Theses and Dissertations within Malaysia Context."

87. Alan Dix, "Human-Computer Interaction," in Encyclopedia of Database Systems, eds. Ling Liu and M. Tamer ÖZsu (Boston, MA: Springer US, 2009).

88. Mario Pérez-Montoro and Jaume Nualart, "Visual Articulation of Navigation and Search Systems for Digital Libraries," International Journal of Information Management 35, no. 5 (2015): 572-79.

89. Jeffrey Beall, "The Weaknesses of Full-Text Searching," Journal of Academic Librarianship 34, no. 5 (2008): 438-44.

90. Looi and Yeng, "The Inevitable Future of Electronic Theses and Dissertations within Malaysia Context."

91. Daniel Gelaw Alemneh and Ralph Hartsock, "Theses and Dissertations from Print to ETD: The Nuances of Preserving and Accessing those in Music," in Cases on Electronic Records and Resource Management Implementation in Diverse Environments, ed. Janice Krueger, 41-60 (2014), doi:10.4018/978-1-4666-4466-3.ch003. 
92. Edminster and Moxley, "Graduate Education and the Evolving Genre of Electronic Theses and Dissertations," 89-104.

93. Joachim Schöpfel, "Anrt Lille: The French National Centre for the Reproduction of PhD Theses," Interlending \& Document Supply 41, no. 1 (2013): 3-6.

94. Ibid.

95. Joan K. Lippincott, "Institutional Strategies and Policies for Electronic Theses and Dissertations," EDUCAUSE Center for Applied Research, Research Bulletin, no. 13 (2006): 1-12.

96. Rasuli, Alipour-Hafezi, and Solaimani, "Understanding Electronic Theses and Dissertations through a Business Model: Perspective: The Case of Irandoc ETDs."

97. https://pishineh.irandoc.ac.ir/ [accessed 20 September 2018 ].

98. Lynch and Lippincott, "Institutional Repository Deployment in the United States as of Early 2005," 1-11. 99. Schöpfel and Soukouya, "Providing Access to Electronic Theses and Dissertations"; Williams E. Nwagwu, "Open Access Initiatives in Africa: Structure, Incentives and Disincentives," Journal of Academic Librarianship 39, no. 1 (2013): 3-10.

100. Lagzian, Abrizah, and Wee, "An Identification of a Model for Digital Library Critical Success Factors," 5-23; Lagzian, Abrizah, and Wee, "Critical Success Factors for Institutional Repositories Implementation," 196-209.

101. Mary R. Barton and Margaret M. Waters, "Creating an Institutional Repository: LEADIRS Workbook," (Cambridge: Massachusetts Institute of Technology [MIT], 2004), available online at http://hdl.handle. net/1721.1/26698 [accessed 13 November 2018].

102. Bernard Wong and David Tein, "Critical Success Factors for ERP Projects," (Research Gate, January 2003).

103. Sam Solaimani, “The Alignment of Business Model and Business Operations within Network-Enterprise Environments," (doctoral thesis, Delft University of Technology, The Netherlands, 2014), available online at http:// repository.nyenrode.nl/record/frisid:12432 [accessed 13 November 2018].

104. Marikka Heikkilä et al., "Business Model Metrics: An Open Repository," Information Systems and eBusiness Management 14, no. 2 (2016): 337-66.

105. Anthony Troman, Neil Jacobs, and Susan Copeland, "A New Electronic Service for UK Theses: Access Transformed by Ethos," Interlending \& Document Supply 35, no. 3 (2007): 157-63.

106. Emmanuel E. Baro, Vera Z. Godfrey, and Monica E. Eze, "Electronic Theses and Dissertations Initiatives: A Survey of University Libraries in Nigeria," International Information \& Library Review 46, no. 1/2 (2014): 41-50.

107. Alan Carbery, "Implementing an ETD Policy in Wit Libraries," SCONUL Focus 46 (2009): 44-47.

108. Sevim McCutcheon et al., "Morphing Metadata: Maximizing Access to Electronic Theses and Dissertations," Library Hi Tech 26, no. 1 (2008): 41-57.

109. P. Sankar, S. Sudha, and E.S. Kavitha, "Approaches to Shodhganga: A Reservoir of Indian Theses," International Journal of Applied Research 1, no. 13 (2015): 95-99.

110. Joachim Schopfel et al., "Open Access to Research Data in Electronic Theses and Dissertations: An Overview," Library Hi Tech 32, no. 4 (2014): 612.

111. Makoto Shuto et al., "Possibilities of Networked Electronic Theses in Japan," Library Management 35, no. 4/5 (2014): 375-86.

112. Cedar C. Middleton, Jason W. Dean, and Mary A. Gilbertson, "A Process for the Original Cataloging of Theses and Dissertations," Cataloging E Classification Quarterly 53, no. 2 (2015): 234-46.

113. Susan Gasson, "Supporting Quality Timely PhD Completions: Delivering Research Outcomes," Quality in Higher Education 21, no. 1 (2015): 79-88.

114. Wm. Joseph Thomas, Barbara Chen, and Gail Clement, "ORCID Identifiers: Planned and Potential Uses by Associations, Publishers, and Librarians," Serials Librarian 68, no. 1/4 (2015): 332.

115. Janice El-Bayoumi and Lisa Charlong, "The University of New Brunswick's Pilot for an Electronic Theses and Dissertation Program," in Proceedings of the 31st Annual ACM SIGUCCS Conference on User Services, (New York: ACM Press, 2003): 240-246.

116. Kathie Gossett, "Designing an Archive for Born-Digital Dissertations," in Proceedings of the 33rd Annual International Conference on the Design of Communication, Limerick, Ireland-July 16-17, 2015 (New York: ACM, 2015), doi: $10.1145 / 2775441.2775481$. 